\title{
A Propellor-Type Vertical Anemometer ${ }^{1}$
}

\author{
R. M. Holmes, ${ }^{2}$ G. C. GILI ${ }^{3}$ and H. W. CarSON ${ }^{2}$ \\ Canada Department of Agriculture and University of Michigan
}

(Manuscript received 26 May 1964, in revised form 6 August 1964)

\begin{abstract}
A vertical anemometer of the propellor type is described. The instrument is sensitive and economical and output is acceptable to most zero-center millivolt recorders. The voltage output reverses in polarity when the direction of rotation reverses (updrafts or downdrafts).
\end{abstract}

\section{Introduction}

During the past fifteen years several anemometers have been developed for measuring the vertical component of the wind. An Australian group has used hot wire anemometers with success (McIlroy, 1961; Swinbank, 1950). However, calibration drift and extreme fragility are against the widespread use of such instrumentation. Other workers have used bivanes (Cramer and Record, 19534,5; Gill, 1956), pressure spheres, ${ }^{6}$ tethered balloons (Thompson, 1962), and sonic anemometers (Kaimal and Businger, 1963), ${ }^{7}$ with success. Rather elaborate translation and interpretive devices are necessary with these instruments. Thornthwaite designed a fairly rugged propellor type vertical anemometer that incorporates a light chopper with the propellor sensor. The output is translated through a system of relays. ${ }^{8}$ Gill has made a prototype instrument consisting of an array of three propellors, each one turning a light chopper. ${ }^{9}$ The present paper describes a propellor type vertical anemometer similar in con-

\footnotetext{
${ }^{1}$ Joint Contribution of the Plant Research Institute, Research Branch, Canada Department of Agriculture, Ottawa (No. 382), and Department of Meteorology and Oceanography, University of Michigan, Ann Arbor, Mich

2/Agro-Meteorological Section, Plant Research Institute, Canada Department of Agriculture, Ottawa.

\$,Department of Meteorology and Oceanography, University of Michigan, Ann Arbor, Mich.

- Bendix Systems Division, Gelman-Gill Anemometer Bivane, Jungle Canopy Penetration, Vol. III, report \# BSC 36176 to Dept. Army, contract $(D A-42-007-530$, Aug. 1961 to Jan. 1963.

'Meteorological Research, Inc. 1962. A Vectorvane. 2420 Lake Ave., Altadena, Calif.

- Flow Corporation. 1963. A Dynamic Wind Vector Indicator, 205 Sixth Street, Cambridge, Mass.

${ }^{7}$ Stewart, R. M., and R.E. Post. 1962: Sonic anemometer data acquisition and analysis system and calculation of Eulerian scale of turbulence from bivane data. ASTIA, Arlington Hall Station, Arlington, Va. contract AD 284964.

Thornthwaite, C. W., W. J. Superior, J. R. Mather and F. K. Hare, 1961: The measurement of vertical winds and momentum flux. Publications in Climatology, 14 (1), Centerton, N. J.

- Author's unpublished data.
}

figuration to Thornthwaite's but with a four-bladed, high-torque propellor that drives a very low friction, low-inertia DC tachometer generator. This permits the output to be measured by almost any zero-center millivolt recorder.

\section{General description}

A complete vertical anemometer is shown in Fig. 1 with a Beckman and Whitley cup-anemometer. Major construction details are indicated in Fig. 2.

The propellor was designed at the University of Michigan and was a helicoid, 9 inches in diameter, with an axial length of 1.25 inches, and a pitch of 360 degrees in $1.03 \mathrm{ft}$. It was cast of expanded polystyrene beads; two castings were fitted together at the hub to produce a four-bladed propellor.

The propellor drives a very small (i.e., $\frac{5}{8} \times \frac{13}{3} \frac{9}{2}$ inch diameter), low-inertia, low-friction DC tachometer gen-



FIG. 1. Complete vertical anemometer shown with a Beckman-Whitley cup anemometer. 




FIG. 2. Major construction details of vertical anemometer.

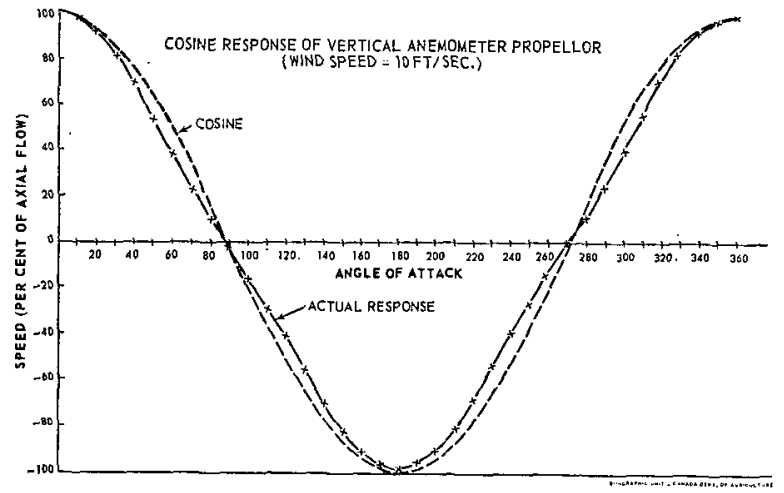

FIG. 3. Relationship of output of vertical anemometer and cosine function for various angles of attack.

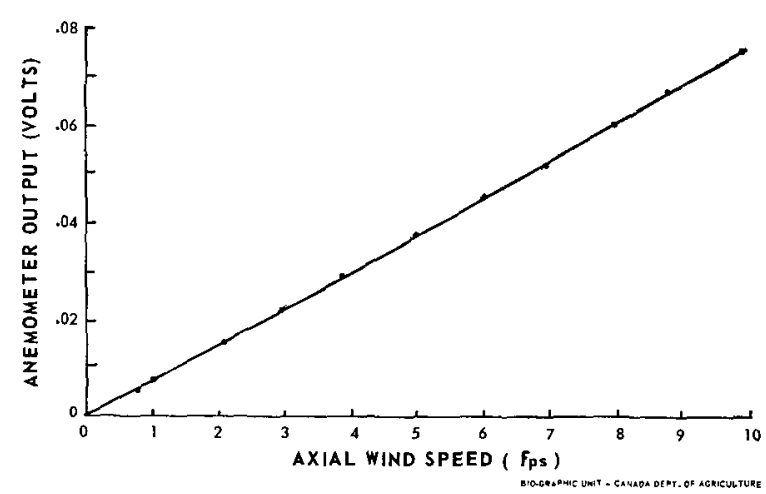

FIG. 4. Relationship between output of vertical anemometer and axial wind speed (zero angle of attack). 


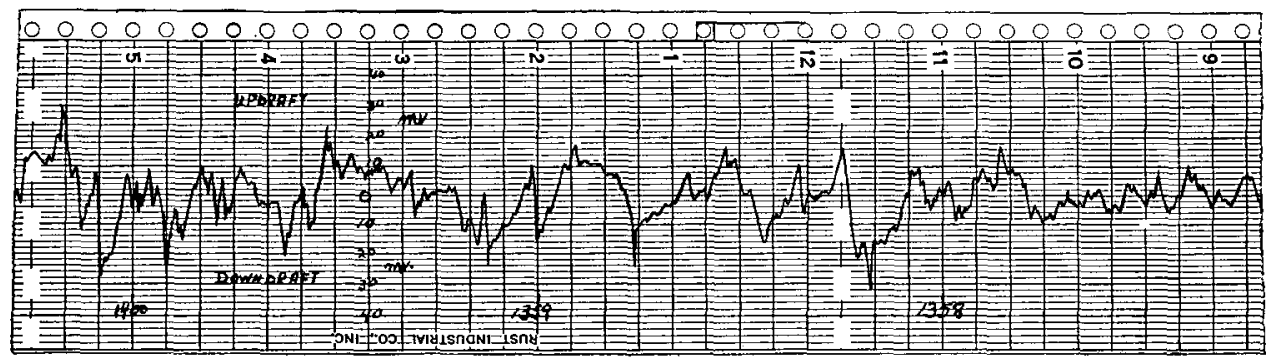

FIG. 5. Three-minute recorder trace of output of vertical anemometer supported 2 meters over corn tassels.

erator via a thin aluminum shaft turning in miniature precision bearings. The horizontal and vertical components for the entire assembly were made of aluminum alloy, The generator and propellor shaft were easily separated for routine cleaning or repair. The shaft was mated with the generator in a spline-universal joint fashion so that no vertical pressure was placed on the generator.

The propellor was insensitive to horizontal air flow (90 deg angle of attack) and linearly responsive to winds normal to the propellor (zero deg angle of attack). At all other angles, the rate of turning was closely in accordance with the cosine of the angle of attack. The degree of adherence of the propellor to the cosine function for various angles of attack is shown in Fig. 3. This calibration curve was for a tunnel speed of $10 \mathrm{ft}$ per second. Calibrations were made for the following tunnel speeds : $0.8,2.1,3.0,5.8,10.0$ and $20.0 \mathrm{ft}$ per sec. The calibration curves for all these speeds were essentially identical with that shown. The greatest error occurred at $60 \mathrm{deg}$ where the rate of turning was approximately 12 per cent less than the true cosine value.

Unlike most anemometers the best-fit straight line through the experimental points passed through the origin, thus no correction was applied for friction or loading (Fig. 4). The meter used had a 100 kilo-ohm input impedance. The DC output reversed in polarity when the direction of rotation reversed (up drafts or downdrafts). The output voltage of the tachometer generator was essentially independent of normal ambient temperature: less than 2 per cent variation over temperature range $+15 \mathrm{~F}$ to $+115 \mathrm{~F}$. The starting speed of the anemometer with the generator removed was $0.1-0.2 \mathrm{mph}$; the starting speed with the generator engaged was $0.2-0.35 \mathrm{mph}$. The unit was exposed to speeds up to $40 \mathrm{mph}$ without damage. The distance constant of the anemometer was $2.1 \mathrm{ft}$ and this remained essentially constant for all angles of attack that were tested.

Two units were used at selected periods during the summer growing season of 1963 over corn plots and no deterioration of performance was noted by the end of that period. The bearings were cleaned at the end of the summer by immersing the shaft and bearing section in an ultrasonic cleaning bath. The entire unit was constructed for approximately $\$ 275$.

A three-minute section of recorder trace shows that the anemometer responds to the fine eddy structure of the atmosphere (Fig. 5).

\section{Summary}

A rugged propellor-type vertical anemometer is described. The output of the instrument was in millivolts with polarity depending upon the direction of rotation of the propellor, that is, upon whether it is in an upor down-current of air. The rate of turning of the propellor was linearly proportional to wind speeds normal to the blades and closely follows the cosine function for all other angles of attack. The unit was relatively inexpensive, as regards initial cost and operation. The output was adequate to drive relatively inexpensive millivolt or milliampere recorders.

\section{REFERENCES}

Cramer, H. E., and F. A. Record, 1953: The variations with height of the vertical flux of heat and momentum. J. Meteor., 10, 219-226.

Gill, G. C., 1956: MIT bivane, potentiometer type. Encyclopedia of instrumentation for industrial hygiene, Ann Arbor, Mich., University of Michigan Press, pp. 627-631.

Kaimal, J. C., and J. A. Businger, 1963: A continuous wave sonic anemometer-thermometer. J. appl. Meteor., 2, 156-164.

McIlroy, J. C., 1961 : Effects of instrumental response on atmospheric flux measurement by the eddy-correlation method. Div. Meteor. Phys. Tech. Paper 11 CSIRO, Melbourne, Australia.

Swinbank, W. C., 1950: The measurement of vertical transfer of heat and water vapor by eddies in the lower atmosphere. I. Meteor., 8, 135-145.

Thompson, N., 1962: Intensities and spectra of vertical wind fluctuation at heights between 100 and $500 \mathrm{ft}$ in neutral and unstable conditions. Quart. J. R. meteor. Soc., 88, 328-334. 